\title{
SPEN protein expression and interactions with chromatin in mouse testicular cells
}

\author{
Joanna Korfanty ${ }^{1}$, Tomasz Stokowy², Marek Chadalski ${ }^{1}$, Agnieszka Toma-Jonik¹, Natalia Vydra, \\ Piotr Widłak' ${ }^{1}$ Bartosz Wojtaśs ${ }^{3}$, Bartłomiej Gielniewski ${ }^{3}$ and Wieslawa Widlak ${ }^{1}$ \\ ${ }^{1}$ Maria Sklodowska-Curie Institute - Oncology Center, Gliwice Branch, Gliwice, Poland, ${ }^{2}$ Department of Clinical \\ Science, University of Bergen, Bergen, Norway and ${ }^{3}$ Laboratory of Molecular Neurobiology, Neurobiology Center, \\ Nencki Institute of Experimental Biology, PAS, Warsaw, Poland \\ Correspondence should be addressed to W Widlak; Email: wieslawa.widlak@io.gliwice.pl
}

\begin{abstract}
SPEN (spen family transcription repressor) is a nucleic acid-binding protein putatively involved in repression of gene expression. We hypothesized that SPEN could be involved in general downregulation of the transcription during the heat shock response in mouse spermatogenic cells through its interactions with chromatin. We documented predominant nuclear localization of the SPEN protein in spermatocytes and round spermatids, which was retained after heat shock. Moreover, the protein was excluded from the highly condensed chromatin. Chromatin immunoprecipitation experiments clearly indicated interactions of SPEN with chromatin in vivo. However, ChIP-Seq analyses did not reveal any strong specific peaks both in untreated and heat shocked cells, which might suggest dispersed localization of SPEN and/or its indirect binding to DNA. Using in situ proximity ligation assay we found close in vivo associations of SPEN with MTA1 (metastasis-associated 1), a member of the nucleosome remodeling complex with histone deacetylase activity, which might contribute to interactions of SPEN with chromatin.

Reproduction (2018) $\mathbf{1 5 6}$ 195-206
\end{abstract}

\section{Introduction}

Spermatogenesis is temperature dependent in the majority of mammals. It occurs optimally at a temperature substantially lower (by around $4-5^{\circ} \mathrm{C}$ ) than the normal body temperature. Elevated testicular temperature has a detrimental effect on spermatogenesis and can compromise sperm quality and increase the risk of male infertility. The most heat-sensitive spermatogenic cells are spermatocytes (Yin et al. 1997). Results of genomics screening revealed transcriptional repression on a large scale in spermatocytes exposed to the elevated temperature. The Spen gene was found among a few genes upregulated in such conditions (Kus-Liśkiewicz et al. 2013).

SPEN protein was described for the first time as a mouse MSX2-interacting nuclear target protein (MINT) (Newberry et al. 1999) and as a human SMRT/HDAC1associated repressor protein (Shi et al. 2001). It is a large basic protein with an ability to bind in vitro to DNA and RNA, which contains four N-terminal RNA-recognition motifs (RRMs) and a highly conserved SPOC (Spen Paralog and Ortholog C-terminal) domain as well as at least four nuclear localization signals (Newberry et al. 1999). N-terminal part of the mouse SPEN could interact with the osteocalcin gene (Bglap) proximal promoter as well as with several homopolymeric DNA sequences.
However, regulation of osteocalcin expression by SPEN depends on its interactions with other proteins. This includes RUNX2 (runt-related transcription factor 2) via RRM domain and MSX2 (msh homeobox 2) via a centrally located domain MID (MSX2-interacting domain). Binding of SPEN and RUNX2 enhanced osteocalcin transcription while additional interactions with MSX2 suppressed osteocalcin activation mediated by RUNX2 and SPEN (Newberry et al. 1999, Sierra et al. 2004). The RRMs-containing domain of SPEN can also bind to IncRNAs: SRA1 (steroid receptor RNA activator 1) or Xist ( $X$ inactive specific transcript). Hence, SPEN was proposed to be involved in repression of SRA1potentiated steroid receptor transcriptional activity (Shi et al. 2001, Hatchell et al. 2006) and in the X chromosome inactivation mediated by Xist (Chu et al. 2015, McHugh et al. 2015, Moindrot et al. 2015, Monfort et al. 2015). Therefore, it has been suggested that SPEN may serve as a platform that organizes and integrates different factors involved in transcriptional regulation.

Disruption of the Spen gene leads to embryonic lethality due to defects in the formation of the cardiac septum, muscle, fetal liver and pancreas (Kuroda et al. 2003). In adult mice, Spen transcripts were detected, among others, in brain, spleen and thymus; yet, the highest expression was found in testis (Newberry et al. 1999, Shi et al. 2001). However, the role of SPEN 
in spermatogenic cells has not been studied so far. Assuming the putative role of SPEN in the suppression of transcription, we hypothesized the involvement of SPEN in general hyperthermia-related inhibition of gene expression in spermatogenic cells. Here, we aimed to characterize its expression and potential targets and partners in testicular cells.

\section{Materials and methods}

\section{Animals, isolation of spermatogenic cells and heat shock treatment}

Adult (10- to 16-week-old), inbred FVB/N mice, were used for experiments. Whole-body heat treatment was performed in vivo in a water bath at $43^{\circ} \mathrm{C}$ for $30 \mathrm{~min}$ as described earlier (Widlak et al. 2007). We also employed juvenile WT and transgenic males expressing a mutated, constitutively active transcriptionally-competent form of HSF1 (heat shock factor 1) specifically in spermatogenic cells (Widłak et al. 2003, Vydra et al. 2006). For chromatin immunoprecipitation (ChIP) experiments, testicular cells were collected after collagenase type IA ( $1 \mathrm{mg} / \mathrm{mL}$ in RPMI medium) digestion of decapsulated testes, essentially as described in Abou-Haila and Tulsiani (2001). For some experiments, spermatocytes were isolated by unit gravity sedimentation in linear BSA gradients according to Kus-Liśkiewicz et al. (2013). Cells were suspended in $\mathrm{CO}_{2}$ saturated RPMI medium supplemented with $10 \%(\mathrm{v} / \mathrm{v})$ fetal bovine serum, $0.004 \%(\mathrm{v} / \mathrm{v})$ gentamycin (KRKA) and $6 \mathrm{mM}$ sodium lactate (Sigma). For heat shock, equal volumes of $\mathrm{CO}_{2}$ saturated, pre-heated media (to $53^{\circ} \mathrm{C}$ or $60^{\circ} \mathrm{C}$ ) were added to the testicular cells suspensions, which immediately raised their temperature from $32^{\circ} \mathrm{C}$ (physiological temperature) to $38^{\circ} \mathrm{C}$ or $43^{\circ} \mathrm{C}$ respectively. Tubes were submerged in a water bath at the appropriate temperature for an additional 15-30 min (time estimated previously as optimal for activation of the heat shock response mediated by HSF1) (Kus-Liśkiewicz et al. 2013, Korfanty et al. 2014) with recovery at $32^{\circ} \mathrm{C}$ in a cell culture incubator. All animal experiments were carried out according to Polish legislation and were approved by the Local Committee of Ethics and Animal Experimentation at the Medical University of Silesia in Katowice, Poland (Decision No 10/2012) and by the Institutional Animal Care Policy of the Maria Sklodowska-Curie Institute - Oncology Center (Gliwice, Poland).

\section{RNA isolation, CDNA synthesis and RT-PCR}

Total RNA was isolated using the GeneMATRIX Universal RNA Purification Kit (Eurx, Gdańsk, Poland) and digested with DNase I (Worthington Biochemical Corporation, NY, USA). Then, $1 \mu \mathrm{g}$ of RNA was converted into cDNA using oligo-dT and random pentadecamer primers (Stangegaard et al. 2006) and used for RT-PCR as described in detail elsewhere (Kus-Liśkiewicz et al. 2013). The primers used are Spen F: ggctgccttcatcacttacc, R: gaggtctatccacggagctg (detect all transcript variants); HSF1 F: ccagcaacagaaagtcgtca, R: gagctcattcttgtccaggc; Actb F: ggacttcgagcaagagatgg, R: agcactgtgttggcgtacag; $18 s$ rRNA
F: gttggtggagcgatttgtctgg, R: gcagccccggatctaagg; Gapdh F: tggtgaagcaggcatctgagg, R: catgaggtccaccaccctgt.

\section{Subcellular fractionation, protein extraction and Western blotting}

Freshly dissected testes were decapsulated and used for nuclear and cytoplasmic fraction isolation using the NE-PER Nuclear and Cytoplasmic Extraction Reagent (Thermo Fisher Scientific) according to producer's protocol. For the whole testicular extracts, mouse tissues (fresh or frozen on dry ice and stored at $-80^{\circ} \mathrm{C}$ until analysis) were homogenized in five volumes of RIPA buffer consisting of $1 \times$ PBS, $1 \%$ NP-40, $0.5 \%$ SDC, $0.1 \%$ SDS, $1 \mathrm{mM}$ PMSF, $50 \mathrm{mM} \mathrm{NaF}$ and protease inhibitors cocktail (Roche). Supernatants were collected after centrifugation at $20,800 \mathrm{~g}$ for $20 \mathrm{~min}$ at $4^{\circ} \mathrm{C}$. Protein concentration was determined using Bradford method (DC Bio-Rad Assay; Bio-Rad). Proteins (30-50 $\mu$ g) were separated on 6 or $10 \%$ SDS-PAGE gels and transferred to PVDF filters. The filters were blocked for $60 \mathrm{~min}$ in $5 \%$ non-fat milk in TTBS (250 mM Tris- $\mathrm{HCl} \mathrm{pH} 7.5,0.1 \%$ Tween-20, $150 \mathrm{mM} \mathrm{NaCl}$ ) and next incubated at $4{ }^{\circ} \mathrm{C}$ overnight with rabbit anti-SPEN polyclonal primary antibodies (dilution 1:1500-1:3000) raised against human peptide epitopes (corresponding position in mouse NP_062737 reference sequence is given below): (i) from N-terminal sequence, aa 139-284 (HPA015825, Sigma, or PAB20849, Abnova), (ii) from internal sequence, aa 13661416 (ab72266, Abcam or A301-119A, Bethyl Laboratories) or (iii) from C-terminal sequence, aa 3353-3404 (NB100-58799, Novus Biologicals). The primary antibody was detected by an appropriate secondary antibody conjugated with horseradish peroxidase (1:1500-1:5000) and visualized by WesternBright ECL kit (Advansta). Imaging was performed on X-ray film or in G:BOX chemiluminescence imaging system (Syngen). To test antibody specificity, peptide competition assay was performed: primary antibody in working concentration was preincubated for $1 \mathrm{~h}$ at room temperature with a 5-7.5-time excess of the synthetic peptide antigen (Novazym Polska s.c.).

\section{Immunohistochemistry (IHC) and immunofluorescence (IF)}

Tissues dissected from control or heat-shocked FVB/N mouse were fixed overnight in $4 \%$ or $10 \%$ buffered formaldehyde at $4{ }^{\circ} \mathrm{C}$, washed in PBS at $4{ }^{\circ} \mathrm{C}$, dehydrated, paraffin-embedded and sectioned $(6-8 \mu \mathrm{m})$ as described elsewhere (Widłak et al. 2003). We employed polyclonal, rabbit anti-SPEN antibodies (1:200) described earlier or goat anti-MTA1 (1:70; sc-9446, Santa Cruz Biotechnology with corresponding blocking peptide sc-9446P), overnight, $4^{\circ} \mathrm{C}$ in a humid chamber; all subsequent steps were performed at room temperature. An antigen retrieval step in $0.01 \mathrm{M}$ citrate buffer $\mathrm{pH} 6.0$ was applied before the procedure. Immunohistochemistry with an ImmPRESS anti-rabbit or anti-goat IgG (peroxidase) reagent (Vector) was performed according to the manufacturer's guidelines. Diaminobenzidine (DAB) was used as a chromogen for visualization of immunohistochemical reactions and hematoxylin was used for counterstaining. Immunofluorescence analyses were performed using a primary 
antibody against the internal region of SPEN (1:500; A301119A, Bethyl Laboratories) and Alexa Fluor 647 Tyramide SuperBoost Kit, goat anti-rabbit IgG (B40926, Invitrogen) according to the user guide. The DNA was stained with DAPI. Images were captured at $\times 630$ magnification using Zeiss Axio Imager.M2 fluorescent microscope with AxioCam camera and AxioVision (Rel.4.8) imaging system or Carl Zeiss LSM 710 confocal microscope with ZEN navigation software. Negative controls were performed in parallel for specific labeling by omitting the primary antibody or by the peptide competition. For the latter one, the primary antibody in working concentration was preincubated for $1 \mathrm{~h}$ at room temperature with a 5-time excess of the synthetic peptide antigen.

\section{Chromatin immunoprecipitation}

The ChIP assay was carried out according to the protocol of a ChIP kit from Upstate Biotechnology (Lake Placid, NY, USA) using protein A-sepharose beads (Amersham). The standard cross-linking procedure was used. For each IP reaction $50 \mu \mathrm{g}$ of chromatin sonicated to 100-500 bp fragments and $5 \mu \mathrm{g}$ of anti-SPEN (N-terminal PAB20849, Abnova; internal ab72266, Abcam; C-terminal NB100-58799, Novus Biologicals) polyclonal antibodies or IgG from rabbit serum (Sigma) as a negative control were used. Immunoprecipitated DNA was additionally digested by RNase A (in a final concentration $70 \mu \mathrm{g} / \mathrm{mL}, 30 \mathrm{~min}, 37^{\circ} \mathrm{C}$ ) before Proteinase $\mathrm{K}$ treatment, de-cross-linking by heat and organic solvent extraction. Glycogen $(70 \mu \mathrm{g} / \mathrm{mL})$ was added at the precipitation step. DNA was dissolved in $\mathrm{H}_{2} \mathrm{O}$. Prior to ChIP-Seq, DNA fragment quantification was analyzed using Agilent Technologies 2100 Bioanalyzer (DNA 1000 chip, range from 100 to 500 bp).

\section{High-throughput sequencing, data analysis and functional annotation}

In each experimental point, five to six ChIP replicates (from 250 to $300 \mu \mathrm{g}$ of input chromatin) were collected and combined in one sample before DNA sequencing. As a negative control, ChIP DNA obtained with IgG was sequenced (since 10-30 ng were required, IgG samples from each experimental point were pooled together and treated as one sample). Input DNA (an equal mixture of all samples) was sequenced as an additional control. Samples were sequenced by Macrogen (Seoul, Korea) or in Nencki Institute (Warsaw). Sequencing libraries were generated using KAPA library preparation kit (for Illumina) KK8201 or QIAseq Ultra Low Input Library Kit, Qiagen, Cat No./ID: 180492. Template amplification and cluster generation were performed using the TruSeq SBS Kit v3 or v1 and 50 or 65 nucleotides were sequenced with Illumina HiSeq 2000 or HiSeq 1500, respectively. After quality filtering (average phred >30) and removal of duplicates, reads were mapped to the mouse genome (mm10) with Bowtie2 (Langmead et al. 2009). A five-fold enrichment over negative control was set as a cutoff criterion for target sites. The peaks were called with Model-based Analysis of ChIP-Seq (MACS) 1.4.2 (Feng et al. 2012). SPEN target sites were annotated to genomic regions using HOMER software (Heinz et al. 2010). Fifty percent of peak length was centered on the summit point, and peaks that fell on exon-intron boundaries are indicated as exons. The density signals of SPEN on the mouse genome was visualized with the Integrative Genomics Viewer (IGV) version 2.2.1 (Thorvaldsdóttir et al. 2013). The high-throughput sequencing data reported in this paper have been deposited in the Gene Expression Omnibus (GEO) database, www.ncbi.nlm.nih.gov/ geo (accession no. GSE99856).

\section{Proximity ligation assay}

To detect the SPEN/MTA1 interactions, the DuoLink in situ proximity ligation assay (PLA) (Olink Bioscience, Uppsala, Sweden) was used according to the manufacturer's protocol. Reactions were performed on sections $(6-8 \mu \mathrm{m})$ of formalinfixed $\left(4 \%\right.$ in $\mathrm{PBS}$, overnight at $\left.4{ }^{\circ} \mathrm{C}\right)$ and paraffin-embedded mouse testes. An antigen retrieval step in $0.01 \mathrm{M}$ citrate buffer $\mathrm{pH} 6.0$ was performed before the procedure. Sections were washed in PBS $(3 \times 5 \mathrm{~min})$, incubated in Blocking Solution (Olink Bioscience) and immunolabeled (overnight, $4^{\circ} \mathrm{C}$ ) with primary antibodies: rabbit anti-SPEN (N-terminal (1:200; PAB20849, Abnova), internal (1:170; A301-119A, Bethyl Laboratories) or C-terminal (1:30; NB100-58799, Novus Biologicals)), and goat anti-MTA1 (1:70; sc-9446, Santa Cruz Biotechnology) diluted in 1\% BSA in PBS; negative controls were proceeded without one primary antibody or both. Then, the secondary antibodies with attached PLA probes (PLA Probe anti-Rabbit PLUS and PLA Probe anti-Goat MINUS; supplied in the DuoLink kit) were used. Signals of analyzed complexes were observed using Zeiss Axio Imager.M2 fluorescent microscope with AxioCam camera and AxioVision (Rel.4.8) imaging system; red fluorescence signal indicated a close proximity $(<40 \mathrm{~nm})$ of proteins recognized by both antibodies (Fredriksson et al. 2002). Images were taken at $\times 1008$ magnification in several focal planes.

\section{Results}

\section{The SPEN protein is preferentially localized in nuclei of spermatocytes and spermatids}

Nascent SPEN is a large protein with a calculated molecular weight of around $400 \mathrm{kDa}$. Two very similar isoforms exist (NP_062737 and NP_001334164), although some shorter, numerically predicted isoforms are also referenced in databases (Fig. 1A). To study the involvement of SPEN in regulation of the transcription in mouse spermatogenic cells, we first looked for the most suitable anti-SPEN antibody. We tested a panel of antibodies against epitopes located in different parts of the protein ( $\mathrm{N}$-terminal, $\mathrm{C}$-terminal and internal regions; Fig. 1A). Results of Western blot analysis of cytoplasmic and nuclear fractions (Fig. 1B) indicate that SPEN could be localized in nuclei and cytoplasm of testicular cells. It is noteworthy that a protein band corresponding to the full-length SPEN (above $300 \mathrm{kDa}$ ) was observed only in part of the Western blot experiments. The antibody against the $\mathrm{N}$-terminal fragment of SPEN preferentially detected $\sim 110 \mathrm{kDa}$ protein fragment in the nuclear fraction (which was favorably detected also in other 


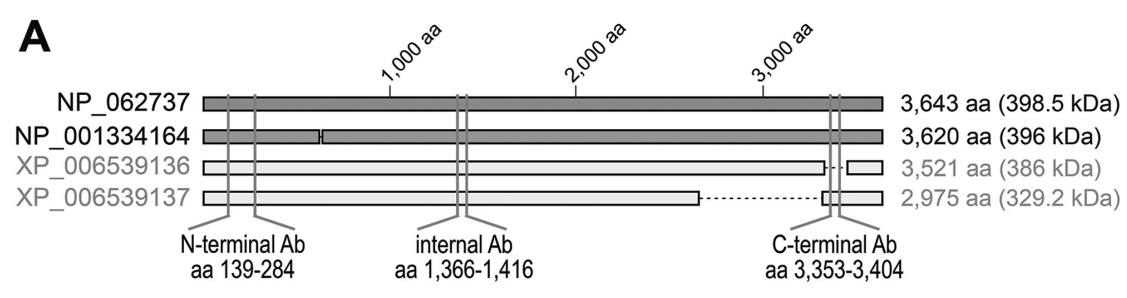

B
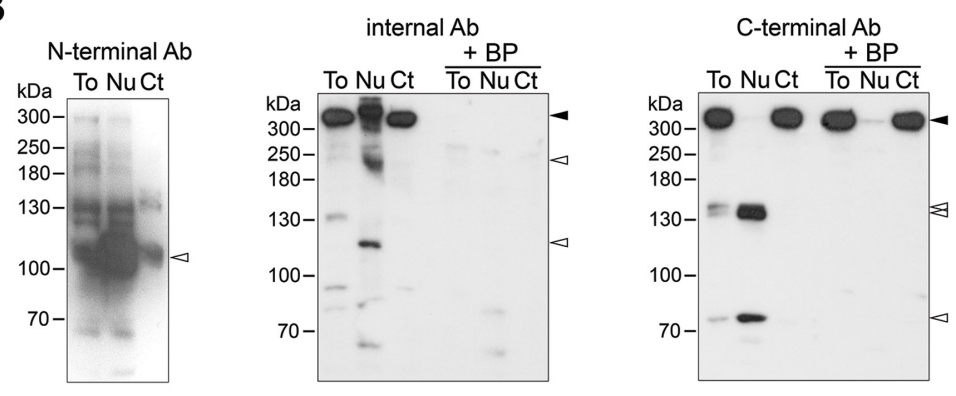

C

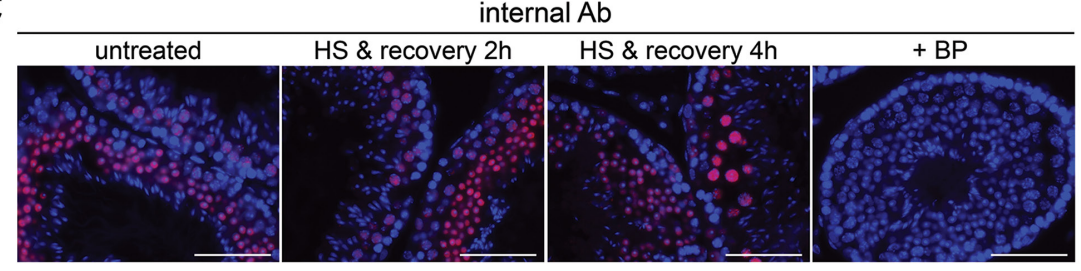

Figure 1 Detection of the SPEN protein in mouse testes. (A) Schematic representation of different mouse SPEN protein isoforms referenced in databases (in light gray - in silico predicted isoforms) and position of epitopes recognized by antibodies. (B) Western blot analysis in the total $(\mathrm{To})$, nuclear $(\mathrm{Nu})$, and cytoplasmic (Ct) fractions of testicular cells using antibodies against $\mathrm{N}$-terminal (overexposed to see the full-length protein), internal, or C-terminal part of the SPEN protein. Solid and empty arrowheads indicate the full-length SPEN and its fragments, respectively; $\mathrm{BP}$, blocking peptide (not available for $\mathrm{N}$-terminal $\mathrm{Ab}$ ). (C) Detection of SPEN by the immunofluorescence (Alexa Fluor 647 , far-red) using antibody against internal part of the protein in control (untreated) testes and in testes collected 2 or $4 \mathrm{~h}$ after heat shock (HS; $43^{\circ} \mathrm{C}$ for $\left.30 \mathrm{~min}\right)$; primarily nuclear localization was documented in all cases. BP - control testes analyzed in the presence of the blocking peptide; DNA is stained with DAPI (blue); scale bar $-50 \mu \mathrm{m}$. mouse organs; not shown). On the other hand, the antibody against the C-terminal epitope detected a large $(>300 \mathrm{kDa})$ band in cytoplasmic fraction and three specific (i.e. blocked in the peptide competition assay) protein bands $(\sim 140, \sim 150$ and $\sim 80 \mathrm{kDa})$ in the nuclear fraction. Protein bands of different sizes were also detected using an antibody against internal part of SPEN, and both 'full' and 'short' fragments (specifically blocked in the peptide competition assay) were detected in the nuclear fraction. Detected 'short' fragments do not correspond to any isoform of the SPEN protein, which suggests that the nascent SPEN protein is rather unstable and could be processed proteolytically to smaller fragments. Nevertheless, antibody to the internal region of SPEN that appeared the most specific (i.e. fully blocked by competing peptide) and recognized a full-length SPEN was selected as the primary probe for further experiments. Using this antibody for immunofluorescence analyses, we showed that nuclear localization of SPEN in mouse testicular cells is maintained following heat shock (Fig. 1C).

It has been reported previously that Spen is highly expressed in testes of adult mouse (Newberry et al. 1999, Shi et al. 2001). However, the expression of SPEN in specific germ cell types has remained unclear. Therefore, we analyzed the developmental pattern of its expression (at the transcript and the protein level) and detailed localization in the seminiferous epithelium by $\mathrm{IHC}$ and
IF using previously characterized antibodies. We found that in mouse testes, abundant Spen transcription started around 18 days of postnatal development (P18, Fig. 2A), which correlates with the appearance of spermatocytes in late pachytene stages of the first meiotic prophase (Bellve et al. 1977). Consistently, IF labeling showed no SPEN protein in testes of 15- and 17-day-old males (P15, P17), and first stained spermatocytes could be found later during development (Fig. 2B). At P21, first SPEN-positive round spermatids were observed. Heatinduced upregulation of Spen reported previously (Kus-Liśkiewicz et al. 2013) indicated the possibility that expression of the Spen gene could be dependent on HSF1, the primary heat-responsive factor. Thus, we took advantage of a mouse strain that expressed a mutated, constitutively active form of HSF1 specifically in spermatogenic cells (HSF1-dependent genes could be induced in these cells at the physiological temperature) (Widłak et al. 2003, Vydra et al. 2006) and analyzed the expression of Spen during postnatal development of transgenic males in parallel with wild-type animals. In the testes of transgenic mice, Spen transcription started earlier than that in wild-type mice, at the same time as the expression of the active HSF1 in early pachytene primary spermatocytes (Fig. 2A). Obtained results confirm that HSF1 can be involved in the heat shockactivated expression of Spen in mouse testes, although the effect is rather moderate. 
A

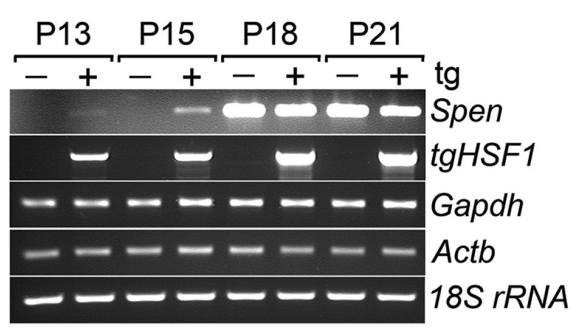

\section{C}
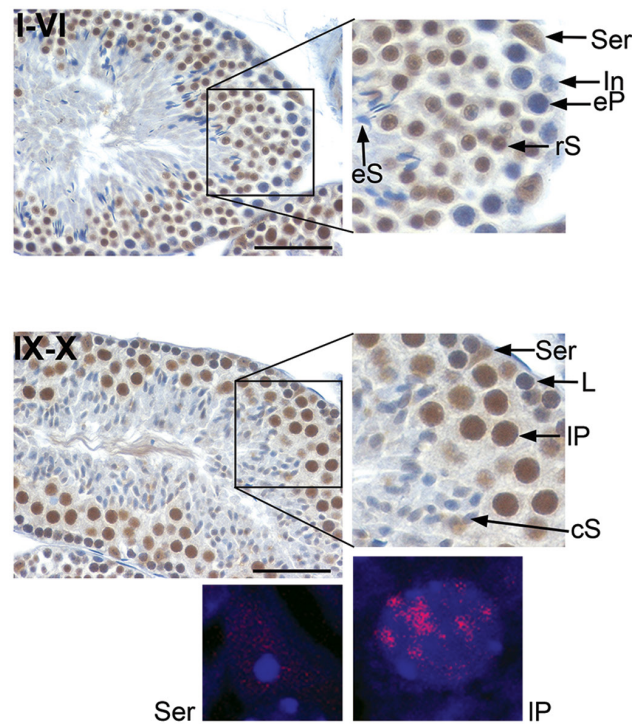

B

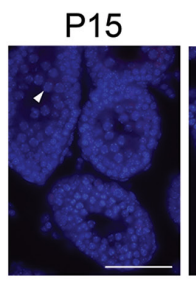

P19

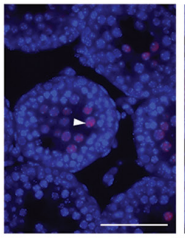

P21

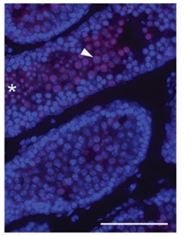

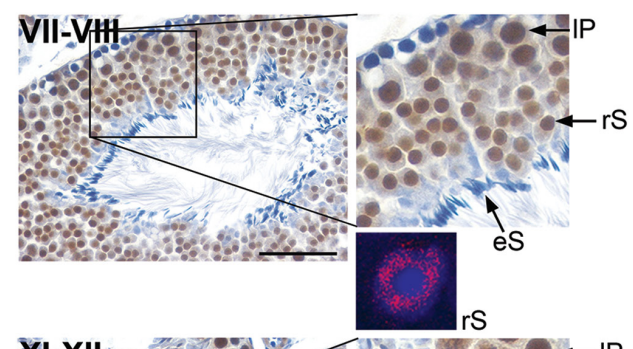

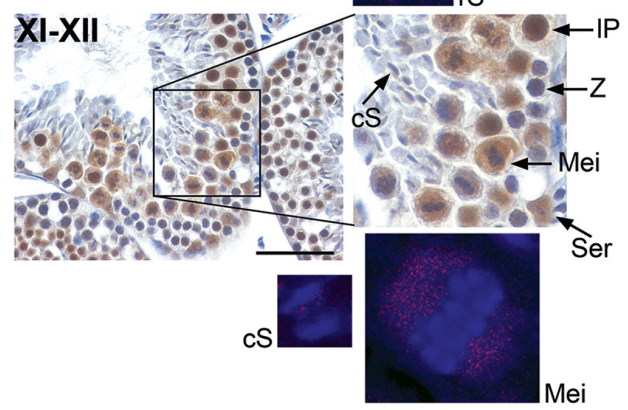

D

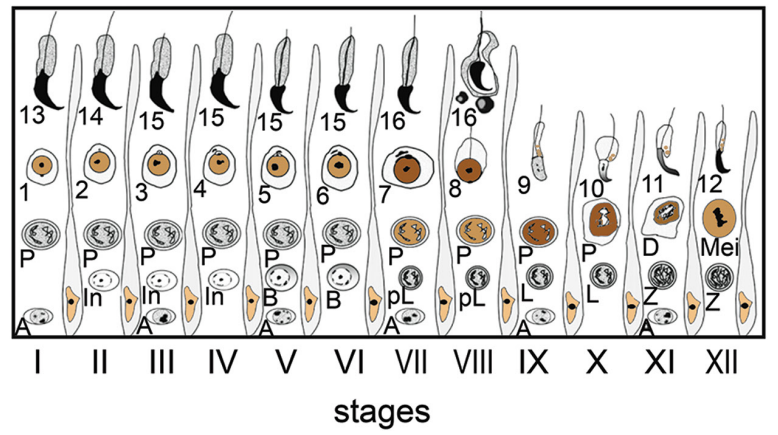

Figure 2 SPEN expression during mouse spermatogenesis. (A) Spen transcription assayed by RT-PCR in testes of wild-type (tg -) and transgenic $(\operatorname{tg}+)$ mice expressing constitutively active, mutated HSF1 (tgHSF1) during postnatal development (P13 to P21 - 13- to 21-day-old males); Gapdh, Actb, $18 S$ rRNA are used as loading controls. (B) Detection of SPEN by immunofluorescence (using antibody against internal part of the protein) in mouse testes during postnatal development (P15 to P21 - 15- to 21-day-old males); DNA is stained with DAPI; white arrowheads show spermatocytes, asterisk - round spermatids; scale bar - $50 \mu \mathrm{m}$. (C) Localization of SPEN in specific cell types (for the legend see panel D) examined by immunohistochemistry using the antibody against internal part of the protein and DAB as a chromogen (brown color). Representative stages of the spermatogenic cycle (classified according to Meistrich \& Hess 2013) are denoted by Roman numerals. Insets show blowups of the selected regions. Details of SPEN distribution in selected types of cells analyzed by IF (Alexa Fluor 647, far-red; DNA stained with DAPI, blue) using confocal microscopy are shown below; scale bar - $50 \mu \mathrm{m}$. (D) A schematic drawing displaying the cell type-specific expression of SPEN (the level of SPEN expression is illustrated by the intensity of the brown color) along the spermatogenic cycle. Each vertical column, separated by Sertoli cells and designated by a Roman numeral, depicts a stage of the seminiferous epithelial cycle and is comprised of a defined set of developing germ cells. The developmental progression of a cell is followed from the bottom row, left to right. Spermatogonia (A, $\mathrm{In}, \mathrm{B})$; spermatocytes: preleptotene $(\mathrm{pL})$, leptotene $(\mathrm{L})$, zygotene $(\mathrm{Z})$, pachytene $(\mathrm{P})$ : early $(\mathrm{eP})$ and late (IP), diakinesis (D), meiotic division (Mei); spermatids (1-16): round (rS), condensing (cS), elongated (eS); Sertoli cells (Ser). 
In mouse testis, based on the cellular composition of seminiferous tubules, 12 specific stages of the spermatogenic cycle have been described (I-XII). Applying stage-identifying criteria proposed by Meistrich and Hess (2013), we performed a detailed analysis of SPEN expression and localization by IHC and IF using internal anti-SPEN antibody (Fig. 2C; Figs 1C and 4C for $\mathrm{Ab}$ specificity). The complete SPEN expression profile in distinct cell types throughout the cycle of the seminiferous epithelium is schematically presented in Fig. 2D. The analysis showed that SPEN is expressed, predominantly in nuclei, in late pachytene spermatocytes (but not in earlier stages of spermatogenic cells what is consistent with developmental studies), during meiosis and round spermatid development. Afterward, strong nuclear staining of SPEN disappears; yet, small traces still can be detected by IF in the cytoplasm of condensing spermatids at stages IX-XII. Moreover, the IF analyses using confocal microscopy revealed that SPEN is excluded from a highly condensed chromatin, especially from the metaphase plate during meiosis and from the chromocenter in the round spermatid (Fig. 2C). The SPEN protein could also be detected in Sertoli cells of adult testes (yet not in juvenile testes), although at the lower level than in spermatogenic cells. Thus, further analyses of SPEN interactions with chromatin performed on the mixture of testicular cells predominantly reflect the situation in spermatocytes and round spermatids.

\section{SPEN demonstrates binding to the chromatin in vivo, yet no specific gene targets are revealed}

Assuming the putative role of SPEN in the hyperthermiamediated gene repression, we searched for hypothetical gene targets of this protein in spermatogenic cells. The antibody directed to the internal part of SPEN (i.e. the most specific in Western blot and IHC/ IF experiments) was used the most extensively for chromatin immunoprecipitation, though antibodies directed to $\mathrm{N}$ - and C-termini were also used. ChIP experiments were performed using chromatin isolated from control (untreated) testicular cells (or their subpopulation enriched with spermatocytes), and cells subjected to mild $\left(38^{\circ} \mathrm{C}\right)$ or severe $\left(43^{\circ} \mathrm{C}\right)$ heat shock, after short exposure $(15$ or $30 \mathrm{~min}$, i.e. the most effective time for assembly on the chromatin of HSF1) and after longer recovery (up to $4 \mathrm{~h}$, i.e. time when hyperthermia-induced effects on gene transcription could be expected). Efficient immunoprecipitation of chromatin was attained with antibodies against internal and $\mathrm{N}$-terminal regions of SPEN; there were 3-9 times more output DNA precipitated than in negative control experiments using IgG. In contrast, the antibody against C-terminus of SPEN showed a much lower efficacy and the amount of output DNA precipitated by this antibody was comparable with the control IgG sample (Fig. 3A). It is noteworthy that if dual cross-linking ChIP protocol recommended for improving immunoprecipitation of protein-DNA complexes (Tian et al. 2012) was used (with disuccinimidyl glutarate), the amount of output material immunoprecipitated with anti-SPEN antibodies was lower than in one step cross-linking (data not shown).

Samples of DNA immunoprecipitated with the antiSPEN antibodies and IgG (as well as input DNA) were subsequently analyzed by deep parallel sequencing. A low number of called peaks characterized with a relatively low peak score to peak width ratio (around 0.3 ) was identified in material immunoprecipitated from either control or heat shocked tissue (Table 1), which indicated relatively weak and dispersed chromatin occupancy by SPEN. This mode of chromatin binding was apparently distinct from HSF1 binding, the primary heat-responsive transcription factor. Heat shockinduced binding of HSF1 to chromatin resulted in increased peak score/width ratio, which particularly increased for binding regions in promoters of classical HSF1 targets (e.g. in Hsp90ab1 promoter a peak score/ width ratio was equal 5.4) (Korfanty et al. 2014). The heat-untreated control sample precipitated with the internal anti-SPEN antibody was the only outlier among ChIP-Seq results regarding the number of called peaks. However, an analogous experiment performed on the spermatocyte-enriched subpopulation of testicular cells, as well as analyses of SPEN binding using $\mathrm{N}$-terminally directed antibody, indicated that untreated control did not significantly differ from other samples (Table 1 ). Since there was no increase in peak calling during the post heat shock recovery time and the outlier sample slightly differed from the rest in a few parameters (i.e. GC content and phred quality score of the raw data), we assume that a high number of called peaks was generated artificially in this particular sample. Visualization of the peaks with the highest scores by the IGV browser indicated that although the peaks scale differed between samples, peaks distribution was comparable to the background signal from input and $\lg \mathrm{G}$ samples (Fig. 3B). Hence, we concluded that though anti-SPEN antibodies (specific for its internal or $\mathrm{N}$-terminal regions) effectively immunoprecipitated chromatin of mouse testicular cells, no prominent peaks of precipitated DNA sequences typical for direct interaction between DNA and sequence-specific transcription factors could be retrieved.

\section{SPEN interacts in vivo with MTA1 protein}

Looking for potential partners that could cooperate with SPEN in mouse testes we focused on interactions previously reported from in vitro studies, which included components of the nucleosome remodeling and deacetylating (NuRD) complex (Shi et al. 2001). Therefore, after analysis of the available data on the expression of the NuRD complex subunits in testicular cells, MTA1 and HDAC2 were initially selected as most 

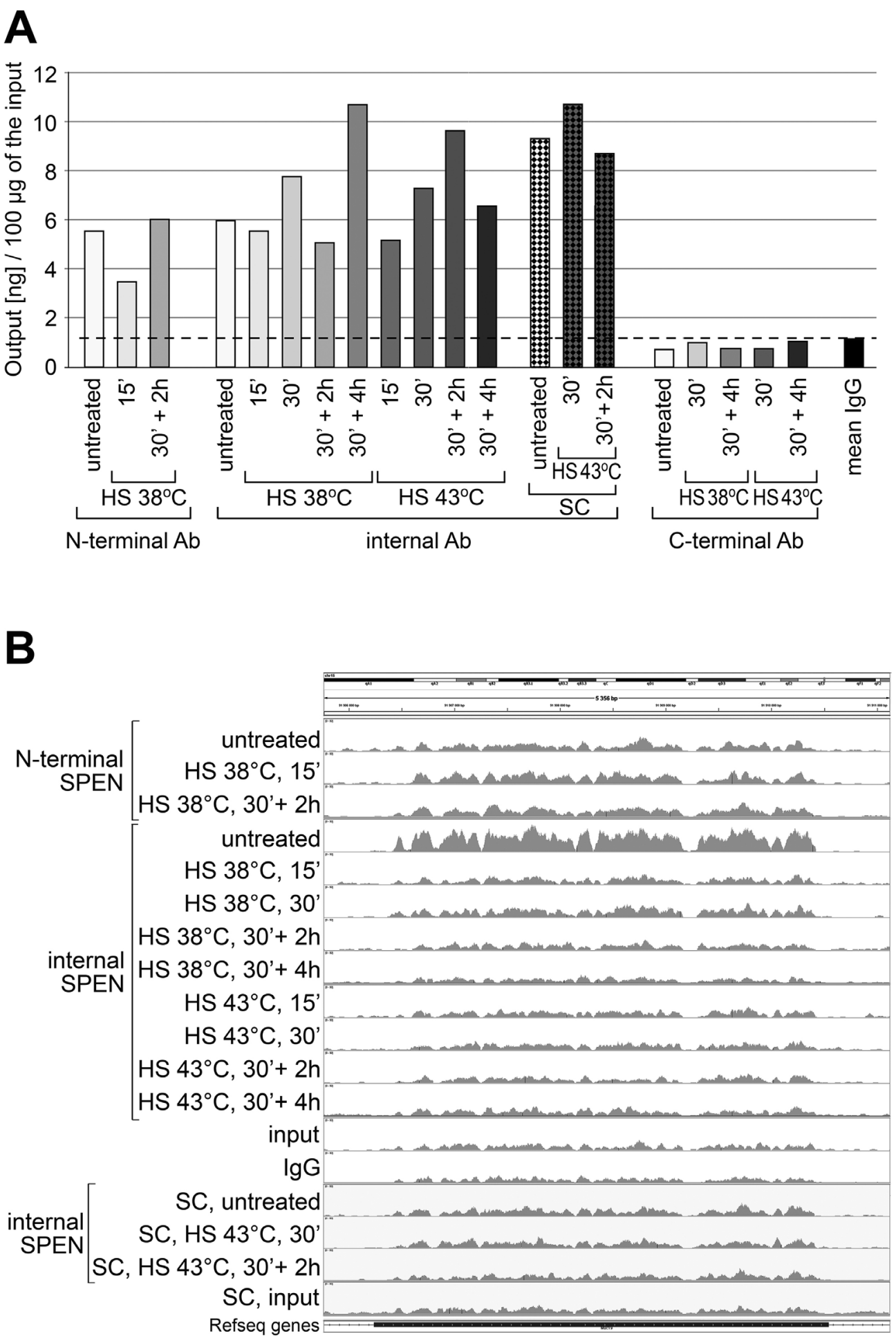

Figure 3 Chromatin immunoprecipitation by anti-SPEN antibodies. (A) Efficiency of immunoprecipitation. (B) Examples of the highest score peaks identified by MACS in ChIP-Seq analyses and visualized by the IGV browser. Anti-SPEN antibodies were used for ChIP in mouse testicular cells or in isolated spermatocytes (SC) at the physiological temperature (untreated) and after heat shock (HS) at $38^{\circ} \mathrm{C}$ or $43^{\circ} \mathrm{C}(\mathrm{HS}$ time in minutes and recovery time in hours). The dashed line in (A) represents the background level of ChIP efficiency with IgG. The region on chromosome 15 ( 5360 bp; chr15: 91,905,750-91,911,160) is shown in (B). The scale for each sample is set to 0-50. Coverage of the same regions in case of input or IgG samples sequencing is shown as a negative control. 
Table 1 Summary of SPEN interactions with chromatin analyzed by ChIP-seq in relation to HSF1, the primary heat-responsive transcription factor (increased HSF1 binding to chromatin in the elevated temperatures results in increased score/width ratio of detected peaks).

\begin{tabular}{|c|c|c|c|c|}
\hline Sample & No of peaks vs IgG & $\begin{array}{c}\text { Peak score/width ratio; } \\
\text { mean } \pm \text { s.D. (median) }\end{array}$ & No of peaks vs input & $\begin{array}{l}\text { Peak score/width ratio; } \\
\text { mean } \pm \text { s.D. (median) }\end{array}$ \\
\hline \multicolumn{5}{|l|}{ ChIP: N-terminal anti-SPEN Ab } \\
\hline 1. Control, untreated & 242 & $0.32 \pm 0.17(0.29)$ & 469 & $0.30 \pm 0.17(0.27)$ \\
\hline 2. $\mathrm{HS} 38^{\circ} \mathrm{C}, 15^{\prime}$ & 292 & $0.31 \pm 0.18(0.29)$ & 599 & $0.30 \pm 0.18(0.28)$ \\
\hline 3. $\mathrm{HS} 38^{\circ} \mathrm{C}, 30^{\prime}+$ rec. $2 \mathrm{~h}$ & 252 & $0.30 \pm 0.23(0.27)$ & 464 & $0.28 \pm 0.18(0.26)$ \\
\hline \multicolumn{5}{|l|}{ ChIP: internal anti-SPEN Ab } \\
\hline 4. Control, untreated & 35,476 & $0.33 \pm 0.07(0.32)$ & 50,008 & $0.34 \pm 0.07(0.34)$ \\
\hline 5. $\mathrm{HS} 38^{\circ} \mathrm{C}, 15^{\prime}$ & 27 & $0.43 \pm 0.22(0.41)$ & 318 & $0.35 \pm 0.21(0.31)$ \\
\hline 6. $\mathrm{HS} 38^{\circ} \mathrm{C}, 30^{\prime}$ & 245 & $0.28 \pm 0.16(0.28)$ & 573 & $0.30 \pm 0.14(0.32)$ \\
\hline 7. $\mathrm{HS} 38^{\circ} \mathrm{C}, 30^{\prime}+$ rec. $2 \mathrm{~h}$ & 36 & $0.35 \pm 0.22(0.28)$ & 366 & $0.32 \pm 0.18(0.30)$ \\
\hline 8. $\mathrm{HS} 38^{\circ} \mathrm{C}, 30^{\prime}+$ rec. $4 \mathrm{~h}$ & 194 & $0.36 \pm 0.18(0.35)$ & 583 & $0.34 \pm 0.20(0.33)$ \\
\hline 9. $\mathrm{HS} 43^{\circ} \mathrm{C}, 15^{\prime}$ & 26 & $0.33 \pm 0.19(0.31)$ & 264 & $0.31 \pm 0.16(0.30)$ \\
\hline 10. $\mathrm{HS} 43^{\circ} \mathrm{C}, 30^{\prime}$ & 25 & $0.40 \pm 0.15(0.36)$ & 399 & $0.33 \pm 0.19(0.32)$ \\
\hline 11. $\mathrm{HS} 43^{\circ} \mathrm{C}, 30^{\prime}+$ rec. $2 \mathrm{~h}$ & 29 & $0.37 \pm 0.19(0.37)$ & 389 & $0.32 \pm 0.18(0.30)$ \\
\hline 12. $\mathrm{HS} 43^{\circ} \mathrm{C}, 30^{\prime}+$ rec. $4 \mathrm{~h}$ & 20 & $0.28 \pm 0.20(0.25)$ & 330 & $0.31 \pm 0.17(0.28)$ \\
\hline 13. Spermatocytes: control, untreated & - & - & 330 & $0.24 \pm 0.16(0.21)$ \\
\hline 14. Spermatocytes: $\mathrm{HS} 43^{\circ} \mathrm{C}, 30^{\prime}$ & - & - & 489 & $0.27 \pm 0.14(0.27)$ \\
\hline 15. Spermatocytes: $\mathrm{HS} 43^{\circ} \mathrm{C}, 30^{\prime}+$ rec. $2 \mathrm{~h}$ & - & - & 382 & $0.25 \pm 0.16(0.24)$ \\
\hline \multicolumn{5}{|l|}{ ChIP: anti-HSF1 Ab* } \\
\hline 1. Spermatocytes: control, untreated & 1562 & $0.32 \pm 0.18(0.26)$ & & \\
\hline 2. Spermatocytes: $\mathrm{HS} 38^{\circ} \mathrm{C}, 5-20^{\prime}$ & 419 & $0.35 \pm 0.18(0.30)$ & & \\
\hline 3. Spermatocytes: $\mathrm{HS} 43^{\circ} \mathrm{C}, 5-20^{\prime}$ & 1645 & $0.56 \pm 0.27(0.52)$ & & \\
\hline
\end{tabular}

*Data extracted from DataSet deposited in Gene Expression Omnibus accession no. GSE56735 (Korfanty et al. 2014).

promising for studies of their interactions with SPEN using the proximity ligation assay (PLA). However, among available goat antibodies, which have to be used for PLA on mouse tissues in pair with rabbit antibody, only anti-MTA1 showed sufficiently specific reactivity in mouse spermatogenic cells (Fig. 4D). PLA analysis revealed close in situ proximity $(<40 \mathrm{~nm})$ of MTA1 and SPEN in chromatin of spermatogenic cells, which indicated that actual interactions between these two proteins are highly probable in vivo (Fig. 4). Similar results were obtained using all previously tested anti-SPEN antibodies (data not shown). Importantly, comparable interactions of SPEN and MTA1 proteins were detected in chromatin of spermatocytes from both control and heat-exposed animals (not shown). Interestingly, SPENMTA1 interactions were not restricted to testicular cells since we observed similar MTA1-SPEN associations in chromatin of mouse brain neurons (not shown).

\section{Discussion}

Because of a lower physiological temperature of testes, the heat shock response in this organ is different than that in somatic tissues. Response to stress, which is primarily mediated by HSF1 (rev. in Vydra et al. 2014), can be activated in spermatogenic cells already at $38^{\circ} \mathrm{C}$ (rev. in Widlak \& Vydra 2017). More importantly, in contrast to somatic cells, where essentially cytoprotective pathways are induced, both elevated temperature and activation of HSF1 have a detrimental effect on spermatogenic cells leading to their apoptosis and subsequent infertility (Nakai et al. 2000, Vydra et al. 2006). General repression of transcription was observed during the heat shock response in mouse spermatogenic cells with relatively few genes being upregulated in such condition, which included Spen (Kus-Liśkiewicz et al. 2013). Assuming the potential role of SPEN-containing complexes in regulation of gene expression we hypothesized that this protein could be involved in global heat-induced suppression of transcription in spermatogenic cells, and we aimed to characterize the in-depth activity of this factor in testes which has not been a subject of published studies yet.

Our data revealed predominant nuclear localization of SPEN protein (in spermatocytes and round spermatids), which was compatible with its putative role as a platform that organizes transcription factors and other components involved in regulation of gene expression (Sierra et al. 2004). Interestingly, however, several protein bands specifically recognized by antiSPEN antibodies (shorter than nascent full-length SPEN) were detected in the nuclear fraction of testicular cells. This observation was in agreement with other reports. In calvarial osteoblasts, the nascent SPEN was processed to mature $110 \mathrm{kDa}(\mathrm{N}$-terminal) and $250 \mathrm{kDa}(\mathrm{C}$-terminal) fragments that both accumulated in chromatin and nuclear matrix fractions (Newberry et al. 1999). Thus, it might be concluded that the full-length SPEN is unstable and could be cleaved (in vivo or during protein extraction procedures) into shorter fragments. In fact, in silico analyses of the mouse SPEN protein sequence using ProtParam tool on the ExPASy Server (Wilkins et al. 1999) has revealed that although the estimated half-life in vivo is $30 \mathrm{~h}$ (in mammalian reticulocytes), 


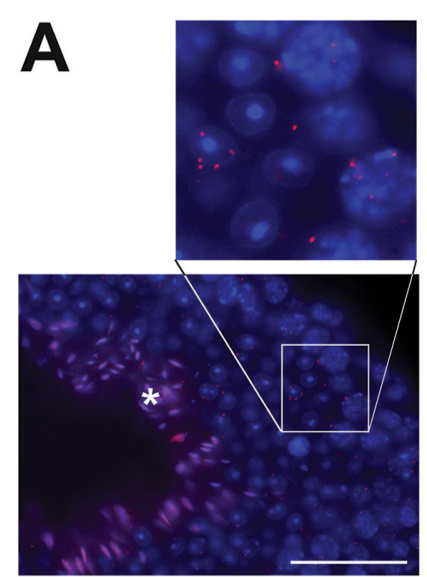

SPEN \& MTA1

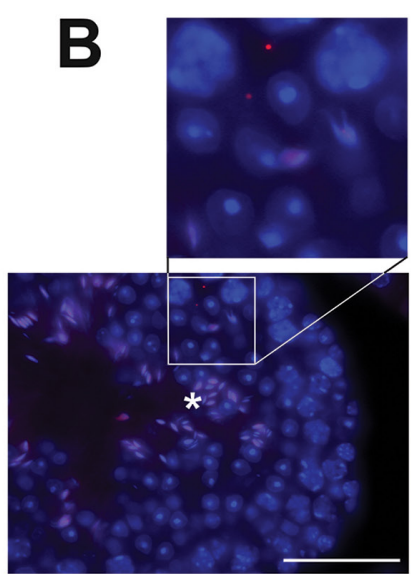

no Ab control

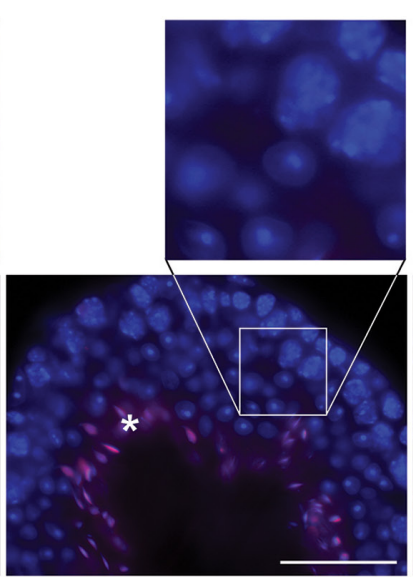

SPEN only

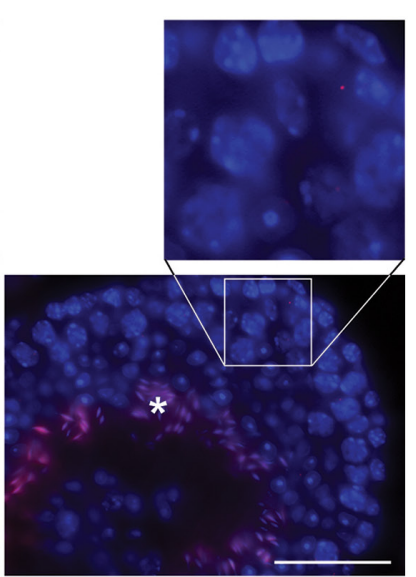

MTA1 only

\section{C}

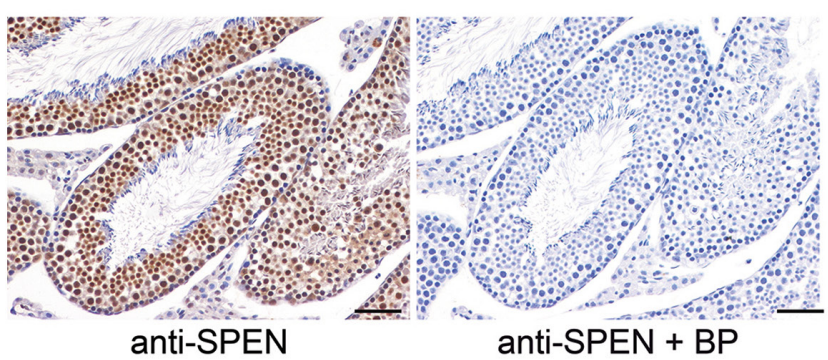

D
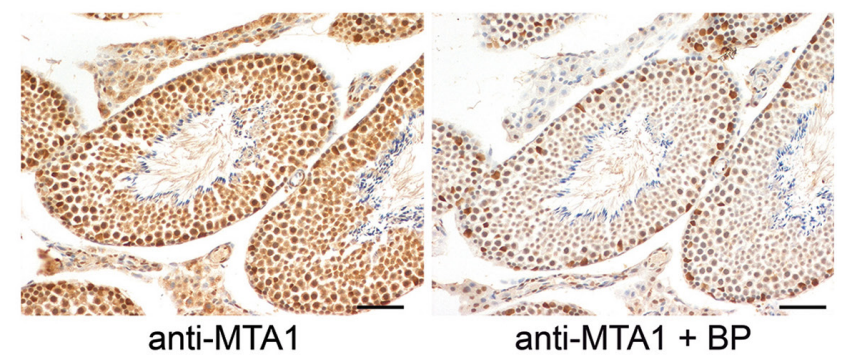

Figure 4 Interactions between MTA1 and SPEN in mouse testes assessed by proximity ligation assay. (A) Testes (seminiferous tubule, stages VII-VIII) probed with antibodies against both SPEN and MTA1. (B) Negative PLA controls. Nuclei are stained with DAPI (blue) and spots of intense fluorescent signals (red) indicate close proteins proximity (unspecific fluorescence from condensing spermatids is pointed by asterisks). Insets show blowups of selected regions (with spermatocytes and round spermatids). (C and D) IHC with DAB staining (brown) on mouse testes showing specificity of the anti-SPEN (using antibody against internal part of the protein) and anti-MTA1 antibodies used in PLA. BP - blocking peptides (unspecific staining in Sertoli cells is visible in the case of anti-MTA1 antibody); scale bar - $50 \mu \mathrm{m}$.

the instability index calculation has classified the protein as unstable in a test tube. Interestingly, it was reported that only the full-length human SPEN enhances $\beta$-catenin-induced activation of T-cell factor-dependent transcription (Feng et al. 2007). On the other hand, due to a large size of SPEN, most of the studies concerning its function were performed in vitro and based on different fragments of the protein. They revealed importance of C-terminal part of SPEN for interactions with other proteins and importance of $\mathrm{N}$-terminal part for interactions with nucleic acids (Shi et al. 2001, Hiriart et al. 2005, Yang et al. 2005, Li et al. 2006, Chu et al. 2015, Monfort et al. 2015). Hence, the functional importance of putative proteolytic processing of SPEN remains unexplained, and their role could depend on the context (gene target and cell type).

Here, we reported the ability of anti-SPEN antibodies to immunoprecipitate chromatin of testicular cells, which together with nuclear localization of SPEN in vivo indicated its potential role as a component of chromatin-associated complexes. Initial aims of current work included identification and characterization of gene targets of SPEN in spermatogenic cells exposed to hyperthermia. However, sequencing of precipitated DNA did not reveal any strong specific target sequences, which would be expected for typical transcription factor directly interacting with its targets. Furthermore, we checked whether detected peaks could be mapped to the blacklisted regions representing frequent artifacts of the next-generation sequencing (data derived empirically from large datasets by the ENCODE consortia; https:// sites.google.com/site/anshulkundaje/projects/blacklists); yet, this type of artifacts appeared in our dataset only occasionally. Instead, detected peaks were frequently mapped to unstable genomic regions commonly referred to as copy number variants (CNVs; accessible in Ensembl database). CNVs can include inversions and balanced translocations or genomic imbalances (insertions and deletions), often overlap with segmental duplications, regions of DNA $>1 \mathrm{~kb}$ present more than once in the genome, copies of which are $>90 \%$ identical (rev. in Cutler \& Kassner 2009). However, any statement whether SPEN preferentially interacts in such regions is premature at that moment, because observed 
phenomenon could be affected by differences between the mouse strains $\mathrm{FVB} / \mathrm{N}$ (used in the current study) and $\mathrm{C} 57 \mathrm{BL} / 6 \mathrm{~J}$ (used for the mouse reference genome). Nevertheless, the observed pattern of sequence peaks detected in chromatin immunoprecipitated by antiSPEN antibodies indicated dispersed (sequence not specific) and/or indirect mode of interaction of SPEN with DNA in vivo.

Several lines of evidence, including results of ChIP experiments provided in this study, indicate that functional interactions of SPEN with DNA in vivo could be indirect and involve several other protein partners or long noncoding RNAs. Numerous SPEN cofactors (which are known to be involved in regulation of gene expression) have been identified in different in vitro screens. These include SMRT (Silencing Mediator for Retinoid and Thyroid receptors) (Shi et al. 2001), nuclear hormone receptor PPARS (peroxisome proliferator activated receptor gamma, PPARG) (Shi et al. 2002), $E R \alpha$ (estrogen receptor $\alpha$ ) (Légaré et al. 2015), RBPJ (recombining binding protein suppressor of hairless) (Oswald et al. 2002, Kuroda et al. 2003, Li et al. 2005), EB2 (Epstein-Barr virus early protein 2) (Hiriart et al. 2005), CRYBP1 (the zinc finger transcription factor aA-crystallin-binding protein 1) (Yang et al. 2005) and the E2 ubiquitin-conjugating enzyme $\mathrm{UbcH} 8$ (Li et al. 2006). Interactions of SPEN with its cofactors additionally depend on the binding of CtIP/CtBP (DNA endonuclease RBBP8 in complex with C-terminalbinding protein) (Oswald et al. 2005) and ETO (eighttwenty-one, RUNX1T1, a runt-related transcription factor) (Salat et al. 2008). Furthermore, SPEN can interact (via the SPOC domain) with members of the NuRD complex including the histone deacetylase core proteins HDAC1 and HDAC2, the metastasis-associated protein MTA2, the methyl-CpG-binding domain protein MBD3, and the histone-binding protein RBBP4 (Shi et al. 2001).

Here, for the first time, we documented in vivo interactions between SPEN and MTA1 - a constituent of the NuRD chromatin remodeling complex (Xue et al. 1998), which could affect transcription of selected genes (Liu et al. 2015). MTA1 is expressed in a variety of adult mouse tissues (Li et al. 2009). In testes, MTA1, similar to SPEN, is predominantly present in the nuclei of pachytene spermatocytes and spermatids (Li et al. 2007). Dynamic interactions of MTA1 with nucleosomes contributing to the mitotic chromatin/chromosome structure transitions at both prophase and telophase have been already demonstrated (Liu et al. 2015); yet, their role in pre- and post-meiotic chromatin is unknown. Both MTA1 and SPEN are excluded from the metaphase plate during cell division and appear to be generally associated with relaxed chromatin in spermatogenic cells. However, a potential mechanistic role of SPEN-MTA1 complexes in chromatin condensation/decondensation processes remains unclear.
It has been proposed that MTA1 is a stress response protein since it is upregulated in various stress-related situations such as inflammation, immunosurveillance, exposure to reactive oxygen species and reactive nitrogen intermediates (rev. in Wang 2014). Heat shock did not induce expression of MTA1 in mouse spermatogenic cells, and MTA1 protein level was decreased a few hours after a treatment. However, a transient protective effect of MTA1 against heat-induced apoptosis was observed, because MTA1-containing complexes acted as negative co-regulators of p53 (Li et al. 2011). Hence, interactions of SPEN with MTA1 could have interesting functional implications that deserve further studies. Interestingly, such interactions could have a more general role because the SPEN-MTA1 complexes were documented here also in the brain neurons.

\section{Declaration of interest}

The authors declare that there is no conflict of interest that could be perceived as prejudicing the impartiality of the research reported.

\section{Funding}

This work was supported by the National Science Centre, Poland (grant numbers 2011/03/N/NZ3/03926, 2014/13/B/ NZ3/04650). The CePT infrastructure financed by the European Union - The European Regional Development Fund within the Operational Programme 'Innovative economy' for 2007-2013 was utilized.

\section{Acknowledgements}

The authors thank Urszula Bojko and Dr Ryszard Smolarczyk for expert technical assistance.

\section{References}

Abou-Haila A \& Tulsiani DR 2001 Acid glycohydrolases in rat spermatocytes, spermatids and spermatozoa: enzyme activities, biosynthesis and immunolocalization. Biological Procedures Online 3 35-42. (https://doi. org/10.1251/bpo21)

Bellve A, Cavicchia J, Millette C, O'Brien D, Bhatnagar Y \& Dym M 1977 Spermatogenic cells of the prepuberal mouse: isolation and morphological characterization. Journal of Cell Biology 74 68-85. (https://doi.org/10.1083/jcb.74.1.68)

Chu C, Zhang QC, da Rocha ST, Flynn RA, Bharadwaj M, Calabrese JM, Magnuson T, Heard E \& Chang HY 2015 Systematic discovery of Xist RNA binding proteins. Cell 161 404-416. (https://doi.org/10.1016/j. cell.2015.03.025)

Cutler G \& Kassner PD 2009 Copy number variation in the mouse genome: implications for the mouse as a model organism for human disease. Cytogenetic and Genome Research 123 297-306. (https://doi. org/10.1159/000184721)

Feng Y, Bommer GT, Zhai Y, Akyol A, Hinoi T, Winer I, Lin HV, Cadigan KM, Cho KR \& Fearon ER 2007 Drosophila split ends homologue SHARP functions as a positive regulator of Wnt/beta-catenin/T-cell factor signaling in neoplastic transformation. Cancer Research 67 482-491. (https://doi.org/10.1158/0008-5472.CAN-06-2314) 
Feng J, Liu T, Qin B, Zhang Y \& Liu XS 2012 Identifying ChIP-seq enrichment using MACS. Nature Protocols 7 1728-1740. (https://doi. org/10.1038/nprot.2012.101)

Fredriksson S, Gullberg M, Jarvius J, Olsson C, Pietras K, Gústafsdóttir SM, Ostman A \& Landegren U 2002 Protein detection using proximitydependent DNA ligation assays. Nature Biotechnology 20 473-477. (https://doi.org/10.1038/nbt0502-473)

Hatchell EC, Colley SM, Beveridge DJ, Epis MR, Stuart LM, Giles KM, Redfern AD, Miles LEC, Barker A, MacDonald LM et al. 2006 SLIRP, a small SRA binding protein, is a nuclear receptor corepressor. Molecular Cell 22 657-668. (https://doi.org/10.1016/j.molcel.2006.05.024)

Heinz S, Benner C, Spann N, Bertolino E, Lin YC, Laslo P, Cheng JX, Murre C, Singh H \& Glass CK 2010 Simple combinations of lineagedetermining transcription factors prime cis-regulatory elements required for macrophage and B cell identities. Molecular Cell 38 576-589. (https://doi.org/10.1016/j.molcel.2010.05.004)

Hiriart E, Gruffat H, Buisson M, Mikaelian I, Keppler S, Meresse P, Mercher T, Bernard OA, Sergeant A \& Manet E 2005 Interaction of the Epstein-Barr virus mRNA export factor EB2 with human Spen proteins SHARP, OTT1, and a novel member of the family, OTT3, links Spen proteins with splicing regulation and mRNA export. Journal of Biological Chemistry 280 36935-36945. (https://doi.org/10.1074/jbc. M501725200)

Korfanty J, Stokowy T, Widlak P, Gogler-Piglowska A, Handschuh L, Podkowiński J, Vydra N, Naumowicz A, Toma-Jonik A \& Widlak W 2014 Crosstalk between HSF1 and HSF2 during the heat shock response in mouse testes. International Journal of Biochemistry and Cell Biology 57C 76-83. (https://doi.org/10.1016/j.biocel.2014.10.006)

Kuroda K, Han H, Tani S, Tanigaki K, Tun T, Furukawa T, Taniguchi $\mathrm{Y}$, Kurooka H, Hamada Y, Toyokuni S et al. 2003 Regulation of marginal zone B cell development by MINT, a suppressor of Notch/RBP-J signaling pathway. Immunity 18 301-312. (https://doi.org/10.1016/ S1074-7613(03)00029-3)

Kus-Liśkiewicz M, Polańska J, Korfanty J, Olbryt M, Vydra N, Toma A \& Widłak W 2013 Impact of heat shock transcription factor 1 on global gene expression profiles in cells which induce either cytoprotective or pro-apoptotic response following hyperthermia. BMC Genomics 14456. (https://doi.org/10.1186/1471-2164-14-456)

Langmead B, Trapnell C, Pop M \& Salzberg SL 2009 Ultrafast and memoryefficient alignment of short DNA sequences to the human genome. Genome Biology 10 R25. (https://doi.org/10.1186/gb-2009-10-3-r25)

Légaré S, Cavallone L, Mamo A, Chabot C, Sirois I, Magliocco A, Klimowicz A, Tonin PN, Buchanan M, Keilty D et al. 2015 The estrogen receptor cofactor SPEN functions as a tumor suppressor and candidate biomarker of drug responsiveness in hormone-dependent breast cancers. Cancer Research 75 4351-4363. (https://doi.org/10.1158/0008-5472. CAN-14-3475)

Li J, Li J, Yang X, Qin H, Zhou P, Liang Y \& Han H 2005 The C terminus of MINT forms homodimers and abrogates MINT-mediated transcriptional repression. Biochimica et Biophysica Acta 1729 50-56. (https://doi. org/10.1016/j.bbaexp.2005.02.001)

Li J, Wang J, Yang X, Li J, Qin H, Dong X, Zhu Y, Liang L, Liang Y \& Han H 2006 The Spen homolog Msx2-interacting nuclear target protein interacts with the E2 ubiquitin-conjugating enzyme UbcH8. Molecular and Cellular Biochemistry 288 151-157. (https://doi.org/10.1007/ s11010-006-9131-9)

Li W, Liu X-P, Xu R-J \& Zhang Y-Q 2007 Immunolocalization assessment of metastasis-associated protein 1 in human and mouse mature testes and its association with spermatogenesis. Asian Journal of Andrology 9 345-352. (https://doi.org/10.1111/j.1745-7262.2007.00245.x)

Li W, Ma L, Zhao J, Liu X, Li Z \& Zhang Y 2009 Expression profile of MTA1 in adult mouse tissues. Tissue and Cell 41 390-399. (https://doi. org/10.1016/j.tice.2009.04.002)

Li W, Wu Z, Zhao J, Guo S, Li Z, Feng X, Ma L, Zhang J, Liu X \& Zhang Y 2011 Transient protection from heat-stress induced apoptotic stimulation by metastasis-associated protein 1 in pachytene spermatocytes. PLoS ONE 6 e26013. (https://doi.org/10.1371/journal.pone.0026013)

Liu J, Wang H, Ma F, Xu D, Chang Y, Zhang J, Wang J, Zhao M, Lin C, Huang C et al. 2015 MTA1 regulates higher-order chromatin structure and histone H1-chromatin interaction in-vivo. Molecular Oncology 9 218-235. (https://doi.org/10.1016/j.molonc.2014.08.007)
McHugh CA, Chen C-K, Chow A, Surka CF, Tran C, McDonel P, Pandya-Jones A, Blanco M, Burghard C, Moradian A et al. 2015 The Xist IncRNA interacts directly with SHARP to silence transcription through HDAC3. Nature 521 232-236. (https://doi.org/10.1038/ nature14443)

Meistrich ML \& Hess RA 2013 Assessment of spermatogenesis through staging of seminiferous tubules. Methods in Molecular Biology 927 299-307. (https://doi.org/10.1007/978-1-62703-038-0_27)

Moindrot B, Cerase A, Coker H, Masui O, Grijzenhout A, Pintacuda G, Schermelleh L, Nesterova TB \& Brockdorff N 2015 A Pooled shRNA Screen Identifies Rbm15, Spen, and Wtap as Factors Required for Xist RNA-Mediated Silencing. Cell Reports 12 562-572. (https://doi. org/10.1016/j.celrep.2015.06.053)

Monfort A, Di Minin G, Postlmayr A, Freimann R, Arieti F, Thore S \& Wutz A 2015 Identification of Spen as a crucial factor for Xist function through forward genetic screening in haploid embryonic stem cells. Cell Reports 12 554-561. (https://doi.org/10.1016/j.celrep.2015.06.067)

Nakai A, Suzuki M \& Tanabe M 2000 Arrest of spermatogenesis in mice expressing an active heat shock transcription factor 1. EMBO Journal 19 1545-1554. (https://doi.org/10.1093/emboj/19.7.1545)

Newberry EP, Latifi T \& Towler DA 1999 The RRM domain of MINT, a novel Msx2 binding protein, recognizes and regulates the rat osteocalcin promoter. Biochemistry 38 10678-10690. (https://doi.org/10.1021/ bi990967j)

Oswald F, Kostezka U, Astrahantseff K, Bourteele S, Dillinger K, Zechner U, Ludwig L, Wilda M, Hameister H, Knöchel W et al. 2002 SHARP is a novel component of the Notch/RBP-Jkappa signalling pathway. EMBO Journal 21 5417-5426. (https://doi.org/10.1093/emboj/cdf549)

Oswald F, Winkler M, Cao Y, Astrahantseff K, Bourteele S, Knöchel W \& Borggrefe T 2005 RBP-Jkappa/SHARP recruits CtIP/CtBP corepressors to silence Notch target genes. Molecular and Cellular Biology 25 10379-10390. (https://doi.org/10.1128/MCB.25.23.10379-10390.2005)

Salat D, Liefke R, Wiedenmann J, Borggrefe T \& Oswald F 2008 ETO, but not leukemogenic fusion protein AML1/ETO, augments RBP-Jkappa/ SHARP-mediated repression of notch target genes. Molecular and Cellular Biology 28 3502-3512. (https://doi.org/10.1128/MCB.0196607)

Shi Y, Downes M, Xie W, Kao HY, Ordentlich P, Tsai CC, Hon M \& Evans RM 2001 Sharp, an inducible cofactor that integrates nuclear receptor repression and activation. Genes and Development 15 1140-1151. (https://doi.org/10.1101/gad.871201)

Shi Y, Hon M \& Evans RM 2002 The peroxisome proliferator-activated receptor delta, an integrator of transcriptional repression and nuclear receptor signaling. PNAS 99 2613-2618. (https://doi.org/10.1073/ pnas.052707099)

Sierra OL, Cheng S-L, Loewy AP, Charlton-Kachigian N \& Towler DA 2004 MINT, the Msx2 interacting nuclear matrix target, enhances Runx2dependent activation of the osteocalcin fibroblast growth factor response element. Journal of Biological Chemistry 279 32913-32923. (https://doi. org/10.1074/jbc.M314098200)

Stangegaard M, Dufva IH \& Dufva M 2006 Reverse transcription using random pentadecamer primers increases yield and quality of resulting cDNA. BioTechniques 40 649-657. (https://doi.org/10.2144/000112153)

Thorvaldsdóttir H, Robinson JT \& Mesirov JP 2013 Integrative Genomics Viewer (IGV): high-performance genomics data visualization and exploration. Briefings in Bioinformatics 14 178-192. (https://doi. org/10.1093/bib/bbs017)

Tian B, Yang J \& Brasier AR 2012 Two-step crosslinking for analysis of protein-chromatin interactions. Methods in Molecular Biology 809 105-120. (https://doi.org/10.1007/978-1-61779-376-9_7)

Vydra N, Malusecka E, Jarzab M, Lisowska K, Glowala-Kosinska M, Benedyk K, Widlak P, Krawczyk Z \& Widlak W 2006 Spermatocytespecific expression of constitutively active heat shock factor 1 induces HSP70i-resistant apoptosis in male germ cells. Cell Death and Differentiation 13 212-222. (https://doi.org/10.1038/sj.cdd.4401758)

Vydra N, Toma A \& Widlak W 2014 Pleiotropic role of HSF1 in neoplastic transformation. Current Cancer Drug Targets 14 144-155. (https://doi.or g/10.2174/1568009614666140122155942)

Wang R-A 2014 MTA1 - a stress response protein: a master regulator of gene expression and cancer cell behavior. Cancer Metastasis Reviews 33 1001-1009. (https://doi.org/10.1007/s10555-014-9525-1) 
Widlak W \& Vydra N 2017 The role of heat shock factors in mammalian spermatogenesis. Advances in Anatomy, Embryology, and Cell Biology 222 45-65. (https://doi.org/10.1007/978-3-319-51409-3_3)

Widłak W, Benedyk K, Vydra N, Głowala M, Scieglińska D, Małusecka E, Nakai A \& Krawczyk Z 2003 Expression of a constitutively active mutant of heat shock factor 1 under the control of testis-specific hst70 gene promoter in transgenic mice induces degeneration of seminiferous epithelium. Acta Biochimica Polonica 50 535-541.

Widlak W, Vydra N, Malusecka E, Dudaladava V, Winiarski B, Scieglińska D \& Widlak P 2007 Heat shock transcription factor 1 down-regulates spermatocyte-specific $70 \mathrm{kDa}$ heat shock protein expression prior to the induction of apoptosis in mouse testes. Genes to Cells 12 487-499. (https://doi.org/10.1111/j.1365-2443.2007.01069.x)

Wilkins MR, Gasteiger E, Bairoch A, Sanchez JC, Williams KL, Appel RD \& Hochstrasser DF 1999 Protein identification and analysis tools in the ExPASy server. Methods in Molecular Biology $112531-552$.

Xue Y, Wong J, Moreno GT, Young MK, Côté J \& Wang W 1998 NURD, a novel complex with both ATP-dependent chromatin-remodeling and histone deacetylase activities. Molecular Cell 2 851-861. (https://doi. org/10.1016/S1097-2765(00)80299-3)

Yang X, Li J, Qin H, Yang H, Li J, Zhou P, Liang Y \& Han H 2005 Mint represses transactivation of the type II collagen gene enhancer through interaction with alpha A-crystallin-binding protein 1. Journal of Biological Chemistry 280 18710-18716. (https://doi.org/10.1074/jbc. M500859200)

Yin Y, Hawkins KL, DeWolf WC \& Morgentaler A 1997 Heat stress causes testicular germ cell apoptosis in adult mice. Journal of Andrology $\mathbf{1 8}$ 159-165.

Received 23 January 2018

First decision 11 March 2018

Revised manuscript received 7 May 2018

Accepted 7 June 2018 